Journal of Animal and Veterinary Advances 11 (8): 1208-1212, 2012

ISSN: $1680-5593$

(C) Medwell Journals, 2012

\title{
Construction of RNAi Expressing Vector Targeting the Goat Prion Protein Gene (PRNP)
}

\author{
Yongjun Li, Wenting Li, Taikun Li, Guangjing Zhang, Jiahui Zhang and Dejun Ji \\ College of Animal Science and Technology, 88 South University Ave., \\ Yangzhou University, Yangzhou, 225009 Jiangsu, China
}

\begin{abstract}
To explore the effect of RNA interference on the suppression of goat prion protein gene $(P R N P)$, small interfering RNA (siRNA) expressing vectors pSilencer4.1-siRNA1 and a negative control pSilencer4.1siRNA2 and the eukaryotic expressing vector pSG5-prion expressing parts of goat prion protein gene were designed and constructed. The recombinants were introduced into Human Embryonic Kidney (HEK) 293T cells mediated by GeneTran. RT-PCR was carried out to detect the expression of prion protein gene. The results showed that RNAi effects induced by pSilencer4.1-siRNA1 could successfully deplete the mRNA expression of goat prion protein gene in $293 \mathrm{~T}$ cells $48 \mathrm{~h}$ after transfection with both vectors compared to the negative control. The findings demonstrated that pSilencer4.1-siRNA1 was constructed successfully to transfer antagonistic substance against goat prion protein gene.
\end{abstract}

Key words: RNA interference, siRNA, prion protein gene, goat, antagonistic, protein

\section{INTRODUCTION}

RNA interference (RNAi) is a promising antiviral strategy (Hu et al., 2002). Small interfering RNA (siRNA) can degrade mRNA which has a complementary sequence to the siRNA by RNAi (Tuschl et al., 1999). The siRNA has been widely used as an experimental tool to investigate the function of target genes because of its convenient, specific and potent gene silencing effect (Miyagishi et al., 2003; De Souza et al., 2006). Moreover, therapeutic application of siRNA targeting the gene of interest has been actively investigated. In addition to siRNA, DNA vectors that transcribe siRNA or short hairpin RNA (shRNA) are also available to induce RNAi. Vector-based approaches and siRNA share the same RNAi pathway but have different properties that affect the efficacy of RNAi-based therapy (Sui et al., 2002; Brummelkamp et al., 2002; Yu et al., 2002).

Prion diseases are a group of transmissible neurodegenerative disorders that include CreutzfeldtJakob Disease (CJD), Gerstmann-Straussler Syndrome (GSS), Kuru and Fatal Familial Insomnia (FFI) in humans as well as goat scrapie and bovine spongiform encephalopathy in animals (Aguzzi and Polymenidou, 2004). These diseases are caused by the conversion of the host cellular Prion Protein $\left(\mathrm{PrP}^{\mathrm{c}}\right)$ into scrapie Prion Protein $\left(\mathrm{PrP}^{\mathrm{Sc}}\right)$, a $\beta$-sheet-rich conformer that is infectious in the absence of nucleic acid (Prusiner, 1998). Researches (Bueler et al., 1993; Mallucci et al., 2002) have shown that the decline of expression level of endogenous $\mathrm{PrP}^{\mathrm{c}}$ could prolong the incubation period of prion diseases. The decline of expression level of goat prion protein gene $(P R N P)$ by RNAi pathway may be an effective method to prevent goat prion disease.

Two research groups (Brummelkamp et al., 2002; Sui et al., 2002) proposed a prospect method to control the gene expression and revealed that gene-specific suppression can be achieved by a DNA vector-based approach in mammalian cells. In this study, researhcers used the similar technology of DNA vector-based RNAi to inhibit the expression of PRNP, for the purpose of obtaining useful vectors and therapeutic approach to control goat prion diseases.

\section{MATERIALS AND METHODS}

Plasmid and cell: The siRNA expressing plasmid pSilencer 4.1-CMVneo was purchased from Ambion/Invitrogen Co., Ltd. The eukaryotic expressing plasmid pSG5 was purchased from Stratagene Co., Ltd. The competent cells of Escherichia coli DH5 $\alpha$ were bought from Tiangen Biotech (Beijing, China) Co., Ltd. The Human Embryonic Kidney (HEK) 293T cells were bought from ATCC (American Type Culture Collection).

Corresponding Author: Yongjun Li, College of Animal Science and Technology, 88 South University Ave., Yangzhou University, Yangzhou, 225009 Jiangsu, China 


\section{Vector constructions}

Design and synthesis of siRNAs: The target sequence of PRNP was searched via online software (http://www. ambion.com/techlib/misc/siRNA-finder.html). After homologue sequences blasting, researchers chose 5'AAAACCTGGCGGAGGGGATGGAA-3' (nucleotides 84106, GenBank Accession No. X74758.1) which was located at the coding sequences of PRNP as the target sites of PRNP. Based on the chosen sites, oligonucleotides named siRNA1 were designed according to the principle recommended by Ambion Online Software. Oligonucleotides named siRNA2 were designed as a negative control based on the other sites of PRNP. The specific restriction site, BamHI site was added to the 5 'end of sense and Hind III site was added to the 5 '-end antisense of strand for insertion into the pSilencer 4.1CMVneo vector. Chemically-synthesized siRNAs were purchased from Invitrogen (Shanghai, China). The sequences of the siRNAs are given in supplemental Table 1 .

siRNAs annealing: The synthesized oligonucleotides were dissolved at a concentration of $100 \mu \mathrm{mol} \mathrm{L} \mathrm{L}^{-1}$. Annealing of complementary oligonucleotides was done in $50 \mu \mathrm{L}$ containing $5 \mu \mathrm{L} 10 \times$ shDNA annealing buffer, $5 \mu \mathrm{L}$ sense chain oligonucleotides $\left(100 \mu \mathrm{mol} \mathrm{L}^{-1}\right), 5 \mu \mathrm{L}$ antisense chain oligonucleotides $\left(100 \mu \mathrm{mol} \mathrm{\textrm {L } ^ { - 1 }}\right)$ and $35 \mu \mathrm{L}^{-1} \mathrm{ddH}_{2} \mathrm{O}$ for $5 \mathrm{~min}$ at $95^{\circ} \mathrm{C}, 5 \mathrm{~min}$ at $85^{\circ} \mathrm{C}, 5 \mathrm{~min}$ at $75^{\circ} \mathrm{C}$ and $5 \mathrm{~min}$ at $70^{\circ} \mathrm{C}$. The annealed DNA fragments were diluted to $20 \mathrm{nmol} \mathrm{L}{ }^{-1}$ for ligation.

Recombination and identification of expressing vectors: The siRNA expressing plasmid, pSilencer 4.1-CMVneo,

\begin{tabular}{lc}
\multicolumn{2}{l}{ Table 1: siRNA template oligonucleotides used in this study } \\
\hline siRNA & Sequence \\
siRNA1 & \\
Sense & 5'-GGATCCAACCUGGCGGAGGAUGGAATT'-3' \\
Antisense & 5'-AAGCTTUUCCAUCCUCCGCCAGGUUTT-3' \\
siRNA2 & \\
Sense & 5'-GGATCCAAGCCACAUAGGCAGUUGGTT-3' \\
Antisense & 5'-AAGCTTCCAACUGCCUAUGUGGCUUTT-3' \\
\hline
\end{tabular}

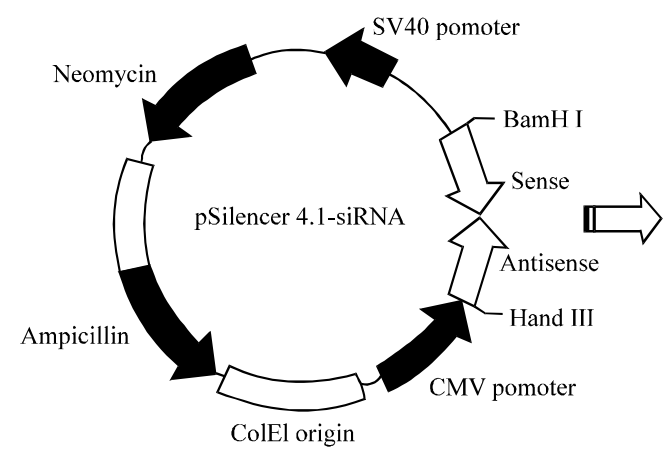

was digested with BamH I and Hind III. Enzyme digestion was done in $50 \mu \mathrm{L}$ containing $5 \mu \mathrm{L}$ $10 \times$ buffer, $2 \mu \mathrm{L}$ BamH I, $2 \mu \mathrm{L}$ Hind III, $2 \mu \mathrm{g}$ pSilencer 4.1 CMVneo and complementary $\mathrm{ddH}_{2} \mathrm{O}$ for $3 \mathrm{~h}$ at $37^{\circ} \mathrm{C}$. The products were electrophoresed on agarose gel and then were recovered using Agarose Gel DNA Purification kit Ver. 2.0 (Takara) according to manufacturer's instructions. Ligation reaction was performed in $16 \mu \mathrm{L}$ containing $2 \mu \mathrm{L}$ $10 \times \mathrm{T} 4$ Ligation buffer, $1 \mu \mathrm{L}$ annealed DNA fragments, $1 \mu \mathrm{L}$ linearized pSilencer4.1-CMVneo vector, $0.5 \mu \mathrm{L}$ T4 DNA ligase and $11.5 \mu \mathrm{L} \mathrm{ddH}_{2} \mathrm{O}$ overnight at $4^{\circ} \mathrm{C}$. The annealed DNA fragments were subcloned into the BamH I and Hind III sites of pSilencer 4.1-CMVneo to act as siRNA templates which will yield hairpin-like siRNAs (Fig. 1). The recombinant plasmids were named as pSilencer 4.1-siRNA1 and pSilencer4.1-siRNA2. According to the designation, the structure and transcribed yields of pSilencer4.1-siRNA1 and pSilencer4.1-siRNA2 are shown in Fig. 1.

The eukaryotic expressing plasmid, pSG5 was digested with EcoR I using similar methodology. The pSG5 vector recovered from agarose gel was treated with CIAP for preventing recircularization of the vector. Total DNA was extracted from goat blood samples using the DNAzol purification kit (Invitrogen) following manufacturer instructions. About $50 \mathrm{ng}$ of genomic DNA was applied to PCR for amplification of target sequence of PRNP. PCR primers (Table 2, PrP) with EcoR I restriction site at 5 '-end were designed from the chosen sequence of PRNP. Ligation reactions employed linearized pSG5 vectors and PCR products. The recombinant plasmids were named pSG5-prion. The structure and transcribed yields of pSG5-prion are shown in Fig. 2.

The competent cells of Escherichia coli DH $5 \alpha$ were transfected with the recombinant plasmids. About $16 \mathrm{~h}$ after transfection, plasmids were extracted from the white clones. The recombinants designated as pSilencer4.1siRNA1, pSilencer4.1-siRNA2 and pSG5-prion were identified with PCR initially and then verified by sequencing. The detecting primers for PCR identification were shown in Table 2 .

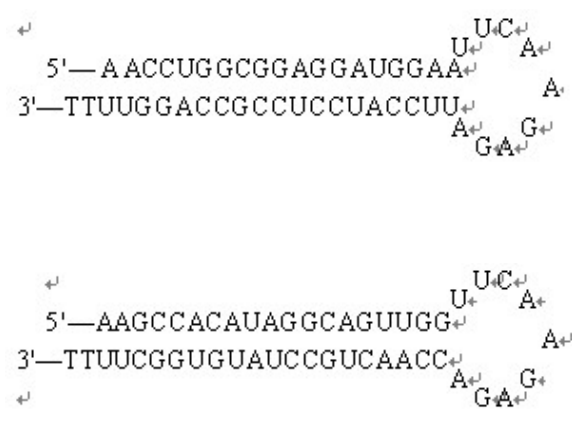

Fig. 1: Schematic diagram of structures and transcribed yields of pSilencer4.1-siRNA1 and pSilencer4.1-siRNA2 and hairpin-like siRNAs 


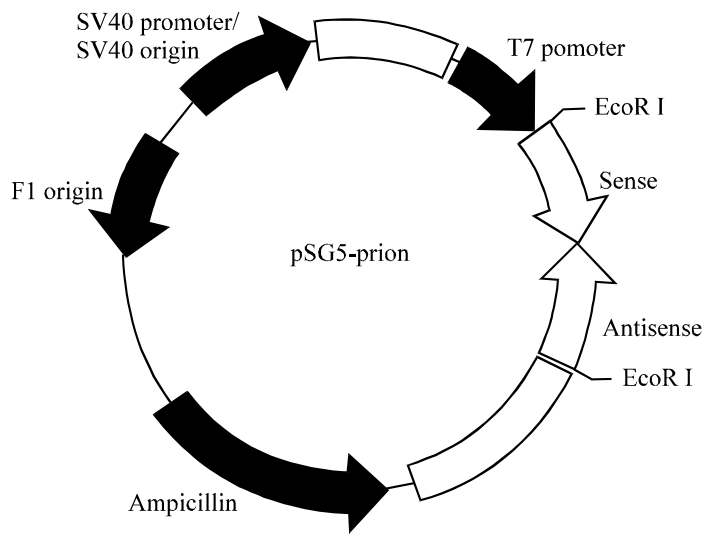

Fig. 2: Schematic diagram of structures and transcribed yields of pSG5-prion

\begin{tabular}{|c|c|c|}
\hline $\begin{array}{l}\text { Primers } \\
\text { designation }\end{array}$ & Sequences & $\begin{array}{l}\text { Anticipate } \\
\text { size (bp) }\end{array}$ \\
\hline \multicolumn{3}{|l|}{ PrP } \\
\hline Forward & 5'-CCGAATTCAGGCGATTAAGTTGGGTA-3' & 250 \\
\hline Reverse & 5'-GCGAATTCCGGTAGGCGTGTACGGTG-3' & \\
\hline \multicolumn{3}{|c|}{ Detecting primer for siRNAs vectors } \\
\hline Forward & 5'-AGGCGATTAAGTTGGGTA-3' & 240 \\
\hline Reverse & 5'-CGGTAGGCGTGTACGGTG-3' & \\
\hline \multicolumn{3}{|c|}{ Detecting primer for pSG5-prion } \\
\hline Forward & 5'-CCAGGCGATTAAGTTGGGTA-3' & 250 \\
\hline Reverse & 5'-GCGGTAGGCGTGTACGGTG-3' & \\
\hline \multicolumn{3}{|c|}{ Human beta-actin } \\
\hline Forward & 5'-TATGTGGGCGACGAGGCCCA-3' & 300 \\
\hline Reverse & 5'- AGTGGTACGGCCAGAGGCGT-3' & \\
\hline
\end{tabular}

Transfection and Reverse Transcriptase PCR (RT-PCR): The Human Embryonic Kidney (HEK) 293T cells were cultured in 6 well plates $\left(1 \times 10^{5}\right.$ cells per well $)$ for $24 \mathrm{~h}$ before transfection in medium lacking penicillin and streptomycin. Cells were cotransfected with pSilencer4.1siRNA1 and pSG5-prion or pSilencer4.1-siRNA2 and pSG5-prion at the ratio of $1: 1$ by using GeneTran (Invitrogen) according to manufacturer's guidelines. After $4 \mathrm{~h}$, the transfection medium was changed to growth medium ( $2 \mathrm{~mL}$ medium per well) containing $0.5 \mathrm{~mL}$ DMEM and $20 \% \mathrm{FBS}$. Cells were harvested at $48 \mathrm{~h}$ after the cotransfection. The total RNA was isolated with Total RNA kit (Tiangen Biotech, China)) and reversetranscribed to complementary DNA (cDNA) using a One Step RT-PCR kit (Takara) according to the manufacturer's instruction. cDNA was applied to PCR for analysis of expression of prion protein gene. PCR reactions were performed with PrP primers (Table 2) and human beta-Actin primers (Table 2) that could quantify the dosage of RNA in different samples.

\section{RESULTS AND DISCUSSION}

Identification of pSilencer4.1-siRNA1 and pSilencer4.1siRNA2: PCR experiments were carried out for the identification of pSilencer4.1-siRNA1 and pSilencer4.1-

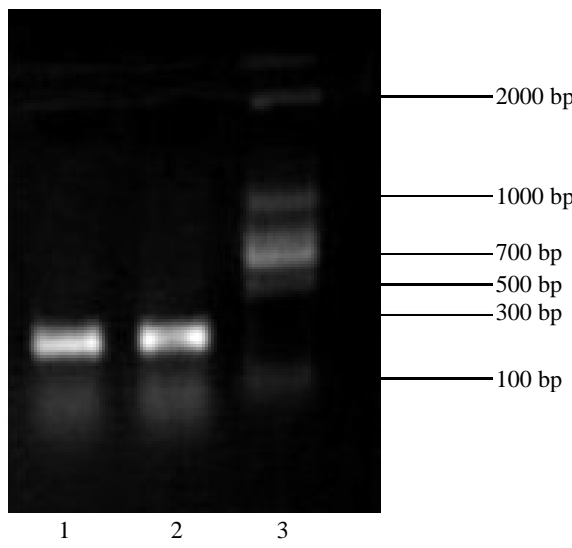

Fig. 3: Identification of pSilencer4.1-siRNAl and pSilencer4.1-siRNA2 with PCR. Lane 1: pSilencer 4.1-siRNA1; Lane 2: pSilencer 4.1-siRNA2 and Lane 3: Marker

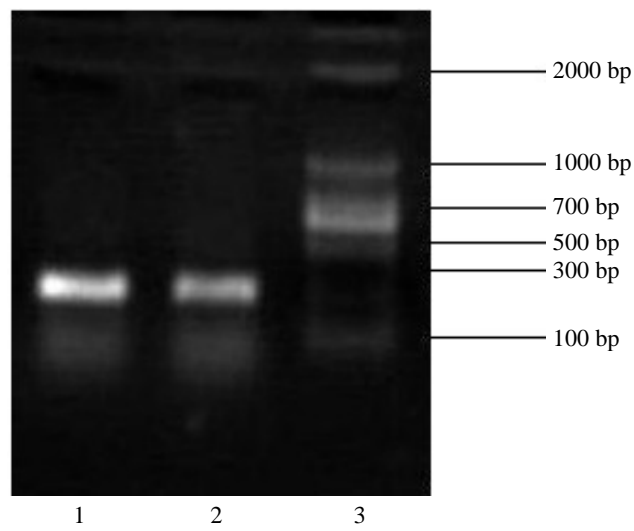

Fig. 4: Identification of pSG5-prion with PCR; Lane 1, 2: pSG5-prion and Lane 3: Marker

siRNA2. As shown in Fig. 3, a fragment about 240 bp can be amplified from DNA of all identified cell clones. The following sequencing confirmed that sample 1 contained the sequence for siRNAl and sample 2 contained the sequence for siRNA2 indicating that the designed DNA templates of siRNAs targeting PRNP were inserted into pSilencer 4.1-CMVneo successfully.

Identification of pSG5-prion: PCR was carried out for the identification of pSG5-prion. As shown in Fig. 4, a fragment about $250 \mathrm{bp}$ can be amplified from DNA of the two identified cell clones. The following sequencing confirmed that these samples contained the target sequence indicating that the target sequence of PRNP was inserted into pSG5 successfully.

Suppression of the expression of prion protein gene in 293T cells: To confirm whether the expression of target 


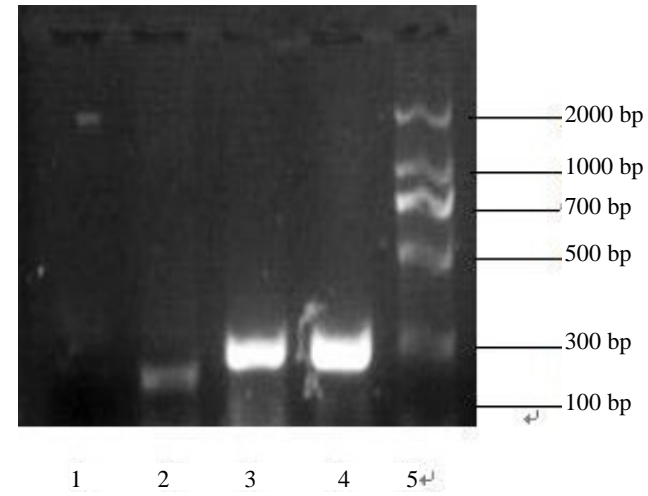

Fig. 5: Suppression of the expression levels of prion protein gene. Lane 1, 3: Cotransfected with pSilencer4.1-siRNA1 and pSG5-prion; Lane 2, 4: Cotransfected with pSilencer4.1-siRNA2 and pSG5-prion; Lane 1, 2: Using PrP primers; Lane 3, 4: Using human beta-actin primers; Lane 5: Marker

sequence of PRNP were suppressed by the recombinant RNAi vectors, RT-PCR was performed based on the total RNA isolated from 293T cells cotransfected with pSilencer4.1-siRNA1 andpSG5-prion, or with pSilencer4.1siRNA2 and pSG5-prion. The figure of electrophoresis on agarose gel showed that the constructed pSilencer4.1siRNAl vector could effectively suppress the the target sequence of PRNP compared to pSilencer4.1-siRNA2, the negative control. PCR performed with human beta-Actin primers yielded $300 \mathrm{bp}$ products (Fig. 5 ).

A DNA vector-based RNAi approach was applied in this study to suppress the expression of the target sequence of PRNP. The sequence of siRNAl is homologous to the target sequence of PRNP so, RNAi effects induced by pSilencer4.1-siRNAl could successfully deplete the mRNA expression of PRNP in $293 \mathrm{~T}$ cells $48 \mathrm{~h}$ after transfection with both vectors compared to the negative control. The siRNA2 could not induce the RNAi effect so, target sequence of PRNP was expressed in 293T cells. The effective pSilencer4.1siRNAl will be the base of further study to breed transgenic goats which are resistant to prion diseases. Each year goat prion diseases cause great economic losses across the world. In order to reduce the economic loss and protect animal and human health, many countries plan to breed transgenic animals which are resistant to prion diseases.

The conformational conversion and subsequent disorders of $\operatorname{PrP}^{\mathrm{Sc}}$ necessitate the presence of $\mathrm{PrP}^{\mathrm{c}}$ (Bueler et al., 1993). A variety of functions have been proposed for mammalian $\mathrm{PrP}^{\mathrm{c}}$ including involvement in cell death and survival, oxidative stress, immunomodulation, differentiation, metal ion trafficking (Pauly and Harris 1998), cell adhesion (Mange et al., 2002) and transmembrane signaling (Linden et al., 2008). But there is no evidence indicating that the deletion of $\operatorname{Pr} P$ gene has deadly effect on mammalian physiology. Target sequence of PRNP was suppressed absolutely in this study. The effect of the pSilencer4.1-siRNAl on expression of complete sequence of PRNP was not validated up to now. The results just provided strong evidence that the approach described above would be useful in suppressing the expression of PRNP.

\section{CONCLUSION}

This study shows that a recombined RNAi vector, pSilencer4.1-siRNA1 with stable suppression of the target sequence of PRNP was reported in this study. The findings provided new insight into preventing goat prion disease and a new method to provide breeding materials for producing therapeutic transgenic goats by somatic cell nuclear transfer.

\section{ACKNOWLEDGEMENTS}

This study was supported by the fund of National Genetically Modified Organisms Breeding Major Projects of China, No. 2009ZX08008-007B.

\section{REFERENCES}

Aguzzi, A. and M. Polymenidou, 2004. Mammalian prion biology: One century of evolving concepts, Cell, 116: 313-327.

Brummelkamp, T.R., R. Bernards and R. Agami, 2002. A system for stable expression of short interfering RNAs in mammalian cells. Science, 296: 550-553.

Bueler, H., A. Aguzzi, A. Sailer, R.A. Greiner, P. Autenried, M. Aguet and C. Weissmann, 1993. Micedevoid of PrP are resistant to scrapie. Cell, 73: 1339-1347.

De Souza, A.T., X. Dai, A.G. Spencer T. Reppen and A. Menzie et al., 2006. Transcriptional and phenotypic comparisons of Ppara knockout and siRNA knockdown mice. Nucleic Acids Res., 34: 4486-4494.

Hu, W.Y., C.P. Myers, J.M. Kilzer, S.L. Pfaff and F.D. Bushman, 2002. Inhibition of retroviral pathogenesis by RNA interference. Curr. Biol., 12: 1301-1311.

Linden, R., V.R. Martins, M.M.A. Prado, M. Cammarota, I. Izquierdo and R.R. Brentani, 2008. Physiology of the prion protein. Physiol. Rev., 88: 673-728.

Mallucci, G.R., S. Ratte, E.A. Asante, J. Linehan, I. Gowland, J.G.R. Jefferys and J. Collinge, 2002. Post-natal knockout of prion protein alters hippocampal CA1 properties, but does not result in neurodegeneration. EMBO J., 21: 202-210. 
Mange, A., O. Milhavet, D. Umlauf, D. Harris and S. Lehmann, 2002. PrP-dependent cell adhesion in N2a neuroblastoma cells. FEBS Lett., 514: 159-162.

Miyagishi, M., M. Hayashi, K. Taira, 2003. Comparison of the suppressive effects of antisense oligonucleotides and siRNAs directed against the same targets in mammalian cells. Antisense Nucleic Acid Drug Dev., 13: $1-7$.

Pauly, P.C. and D.A. Harris, 1998. Copper stimulates endocytosis of the prion protein. J. Biol. Chem., 273: 33107-33110.

Prusiner, S.B., 1998. The prion diseases. Brain Pathol., 8: 499-513.
Sui, G., C. Soohoo, E.B. Affar, F. Gay, Y. Shi, W.C. Forrester and Y. Shi, 2002. A DNA vector-based RNAi technology to suppress gene expression in mammalian cells. Proc. Natl. Acad. Sci., USA., 99: 5515-5520.

Tuschl, T., P.D. Zamore, R. Lehmann, D.P. Barte and P.A. Sharp, 1999. Targeted mRNA degradation by double-stranded RNA In vitro. Genes Dev., 13: 3191-3197.

Yu, J.Y., S.L. Deruiter, D.L. Turner, 2002. RNA interference by expression of short-interfering RNAs and hairpin RNAs in mammalian cells. Proc. Natl. Acad. Sci. USA., 99: 6047-6052. 